\title{
Exercise improves hippocampal estrogen and spatial memory of ovariectomized rats
}

\author{
Kaidah $\mathrm{S}^{1,2}$, Soejono $\mathrm{SK}^{1}$, Partadiredja $\mathrm{G}^{1}$ \\ Department of Physiology, Faculty of Medicine, Universitas Gadjah Mada, Yogyakarta, Indonesia. \\ gpartadiredja@ugm.ac.id
}

\begin{abstract}
OBJECTIVE: The present study aimed at examining the effects of regular exercise on hippocampal estrogen and estrogen receptor $\beta(E R \beta)$ levels, as well as the spatial memory of ovariectomized rats.

BACKGROUND: A decrease of estrogen levels leads to dysfunctions of hippocampus, including spatial learning and memory. Studies have shown that physical exercise improved spatial memory of ovariectomized rats and was associated with an increased extragonadal aromatization. This in turn affects the expression of estrogen receptors.

METHODS: Ovariectomized Sprague Dawley rats were randomly assigned into the two groups, i.e. exercise and control groups. Rats of the exercise group were trained to run on a treadmill. The exercise was performed five times per week for 12 weeks. The spatial memory of rats was measured using the Morris water maze. The hippocampal estrogen and ER $\beta$ levels of rats were determined using ELISA.

RESULTS: The spatial memory retention of the exercise group was significantly better than that of the control group. The hippocampal estrogen level of the exercise group was significantly higher than that of the control group. CONCLUSION: Regular exercise increases hippocampal estrogen levels and improves spatial memory retention of ovariectomized rats (Tab. 1, Fig. 4, Ref. 53). Text in PDF www.elis.sk.

KEY WORDS: ovariectomy, spatial memory, estrogen receptor $\beta$.
\end{abstract}

\section{Introduction}

Estrogen plays a crucial role in regulating physiological functions of organs, including brain (1-3). It has been evidenced that the decrease of estrogen levels in menopausal or post-oophorectomized women led to dysfunctions of hippocampus, which manifested as memory impairment (4-7). Similarly, rats, which underwent ovariectomy, suffered from spatial memory impairment $(8-10)$. While the mechanism involved is not clearly understood, several lines of studies have shown that estrogen treatment in ovariectomized rats and aging females improved spatial memory (11), increased synaptogenesis and induced dendritic spines formations $(12,13)$, facilitated synaptic transmissions

${ }^{1}$ Department of Physiology, Faculty of Medicine, Universitas Gadjah Mada, Yogyakarta, Indonesia, and ${ }^{2}$ Department of Physiology, Faculty of Medicine, Lambung Mangkurat University, Banjarmasin, Indonesia

Address for correspondence: G. Partadiredja, MD, MSc, PhD, Department of Physiology, Faculty of Medicine, Universitas Gadjah Mada, Yogyakarta 55281, Indonesia.

Phone: +62.274 .6492492$

Acknowledgement: The present study was a part of Siti Kaidah's master thesis. It was funded by BPPS scholarship of the Ministry of Education and Culture, Indonesia, and the Faculty of Medicine, Lambung Mangkurat University. The preparation of this manuscript was partially funded by SAME project of DGHE, the Ministry of Education and Culture, Indonesia. The authors would like to thank Rumbiwati (Department of Parasitology) and Suparno (Department of Physiology) of the Faculty of Medicine, Universitas Gadjah Mada, for their technical assistances.
(14), and modulated expressions of neurotrophins such as insulin-like growth factor (IGF) or brain-derived neurotrophic factor (BDNF) (15-17).

Previous studies have shown that physical exercise enhanced cognitive functions of both humans and animals $(18,19)$, as well as improved memory functions of menopausal women $(20,21)$ and spatial learning and memory of rats $(9,21,22)$. The beneficial effects of physical exercise on memory seemed to be related to estrogen levels (23). Regular exercise was reported to increase serum estrogen levels in post-menopausal women (24) and ovariectomized rats (25). It has been suggested that the increase of serum estrogen levels in post-menopausal women and ovariectomized rats following a regular physical exercise is due to extra-gonadal biosynthesis $(26,27)$. Hippocampus is one of organs known to contain enzymes required and capable of carrying out extra-gonadal biosynthesis (28-30).

Studies have shown that estrogen supplementation in rat hippocampal slices culture increased ER $\alpha$ expression (31), but adding estrogen to primary hippocampal neurons culture down-regulated ER $\beta$ expression (32). While several studies have shown the effect of physical exercise on the expression of estrogen receptors in the liver, heart, and muscle tissue $(25,33,34)$, to our knowledge there are no studies devoted to examining the effects of regular exercise on estrogen receptors in hippocampus. It was the aim of the present study to investigate the effects of regular exercise on ER $\beta$ and estrogen levels in hippocampus, as well as the spatial memory of ovariectomized rats. 


\section{Materials and methods}

\section{Animals and reagents}

Ten female Sprague Dawley rats aged 12 weeks, which were initially weighing $162 \pm 3.2 \mathrm{~g}$, were used in this study. The rats were obtained from Animal House of Universitas Gadjah Mada. They were housed in cages under 12-h of natural light-dark cycle. Food and water were given ad libitum throughout the experiment. The experimental protocol and animal handling was approved by the Ethics Committee of Faculty of Medicine, Gadjah Mada University (ethical number KE/FK/375/EC).

After one week of acclimatization, both ovaries of all rats were removed via a $2-3 \mathrm{~cm}$ ventral midline incision on the abdomen under anesthesia (ketamine $\mathrm{HCl} 40 \mathrm{mg} / \mathrm{kg}$ body weight; PT Guardian Pharmatama, Jakarta, Indonesia). Seven days after ovariectomy, the rats were randomly assigned into two groups, i.e. exercise $(n=5)$ and control $(n=5)$ groups.

\section{Exercise training protocol}

The exercise protocol referred to that adopted by Hao et al. (2010) (25) with slight modifications. Briefly, the protocol consisted of two periods, i.e. adaptation period and exercise period. The rats of the exercise group were adapted to the exercise protocol and treadmill apparatus (Gama Tread version 2010, Faculty of Medicine, Universitas Gadjah Mada) for one week. During the adaptation period, the running speed, the treadmill slope, and the duration of exercise were increased gradually. The speed was increased from $10 \mathrm{~m} / \mathrm{min}$ up to $18 \mathrm{~m} / \mathrm{min}$; the slope was increased from $0^{\circ}$ up to $5^{\circ}$; while the duration was increased from 15 minutes up to 60 minutes. Subsequently, during the exercise period, the rats were required to keep running constantly on the treadmill at the speed of $18 \mathrm{~m} / \mathrm{min}$ and at the slope of $5^{\circ}$ for a total duration of $60 \mathrm{~min}$ utes per day. This exercise was performed five times per week for 12 weeks with two days of rest period in each week. The control group was only moved to the training room at the same time when the exercise group performed exercise.

\section{Morris Water Maze task}

The Morris water maze test was carried out according to the protocols described elsewhere (35-37). The test apparatus consisted of a large, white-painted circular pool with a diameter of $150 \mathrm{~cm}$ and a height of $40 \mathrm{~cm}$. The pool was filled with water up to the depth of $18 \mathrm{~cm}$. A circular white platform was placed 2 $\mathrm{cm}$ below the surface of the water. The water was made opaque by adding coconut milk to hide the platform. The temperature of the water was around $25{ }^{\circ} \mathrm{C}$. A video camera was set above the center of the pool and relayed the image of the movements of the animals in the pool to an adjacent laptop computer. Various geometric images with different color were attached to the inner side of the wall of the pool. The pool was divided into four equally imaginary quadrants. Eight equally distanced starting points were marked around the circumference wall of the pool.

The test began 19 days before exercise training finished. Twenty-four hours before trials, the rats were moved to the test room in order to familiarize with the room. On the day of testing, the platform was positioned in the center of randomly chosen quadrant for each rat. One starting point was randomly selected for each trial. The test began when any given rat was placed at this starting point while facing toward the circumference wall of the pool, and then allowed to swim and find ways to escape. It was expected that the rats might accidentally find the hidden platform and climbed on to it.

Escape acquisition test. Each rat was given eight trials each day for 3 consecutive days. The rat was allowed to swim for a maximum of 3 minutes to find the hidden platform at each trial. The time ('escape latency') for the rat to find the platform was recorded. If unsuccessful within 3 minutes, the rat was given a latency score of 3 minutes.

Memory persistence test. To examine the animal ability in retaining the spatial memory about the location of the platform, the rats underwent memory persistence tests twice, i.e. on 'day 10 ' and 'day 17 '. In these tests, the rats were required to perform one trial only per day.

Visible platform test. After the last memory persistence test, for the following two consecutive days, the rats were assigned 'visible platform test' to examine their sensory and motor functions. In this test, the platform was made visible to the rats. In addition, a color flag was attached to the platform. The test consisted of four trials per day, each of which lasted for a maximum of 30 seconds.

All video images of the trials were used for measuring the distances of swimming tracks of the rats. These path lengths were measured using a curvimeter (Map-Meter Comcurve 10, Koizumi Sokki Mfg. Co. Ltd., Japan). The data on latency and swimming distance were then used for further statistical analyses.

\section{Hippocampal tissue collection}

The rats were euthanized under anesthesia (ketamine $\mathrm{HCl}$ $40 \mathrm{mg} / \mathrm{kg}$ body weight; PT Guardian Pharmatama, Jakarta, Indonesia) approximately $24 \mathrm{~h}$ after the last exercise training. The hippocampi of the rats were removed from their skulls and subdivided into left and right parts. Both right and left hippocampi were extracted from the forebrains of the rats in PBS-glucose solution (160 mg glucose in $40 \mathrm{ml}$ PBS ( $\mathrm{pH} 7.4)$ ). The extracted left hippocampus was homogenized in TEGM (Tris-HCl 10mM, EDTA $5 \mathrm{mM}$, glycerol $10 \%$, and $\mathrm{MgCl} 23 \mathrm{mM}$; pH 6.8) and subsequently incubated for $18 \mathrm{~h}$ in a $4{ }^{\circ} \mathrm{C}$ refrigerator. The homogenates were then centrifuged at $1000 \mathrm{x}$ g for 20 minutes, and the supernatants were used for the determination of estrogen receptors $\beta$ concentration. The concentration was determined using rat ER beta ELISA kit (Cusabio Biotech Co., Ltd., PR China) in a Biorad microplate reader (Benchmark, Japan) operated at a wavelength of $450 \mathrm{~nm}$.

The right hippocampus was homogenized in PBS solution and subsequently was incubated for $12 \mathrm{~h}$ in a $-20^{\circ} \mathrm{C}$ refrigerator. The homogenates were then centrifuged at $5000 \mathrm{x} g$ for 5 minutes. The supernatants of these homogenates were used for the examination of estradiol concentration. The concentration was determined using rat estradiol ELISA kit (DRG instruments GmBH, Germany) in a Biorad microplate reader (Benchmark, Japan) operated at a wavelength of $450 \mathrm{~nm}$. 
Tab. 1. the Mean \pm SEM of the body and hippocampal weights of the exercise and control groups of rats.

\begin{tabular}{lccc}
\hline & $\begin{array}{c}\text { Exercise } \\
\text { group }(\mathrm{n}=5)\end{array}$ & $\begin{array}{c}\text { Control } \\
\text { group }(\mathrm{n}=5)\end{array}$ & $\mathrm{p}$ \\
\hline Body Weight $(\mathrm{g})$ & & & \\
\hline Before exercise & $163.80 \pm 2.59 *$ & $160 \pm 6.12 *$ & 0.595 \\
After exercise & $229.60 \pm 12.54 *$ & $230.20 \pm 9.44 *$ & 0.214 \\
Increase of body weight & $65.80 \pm 12.85$ & $70.20 \pm 8.40$ & 0.783 \\
Hippocampal weight (mg) & $221.86 \pm 10.44$ & $238.46 \pm 24.73$ & 0.562 \\
\hline * These raw data were transformed into sine data to obtain normal distribution prior \\
to unpaired t-test analysis
\end{tabular}

\section{Statistical analyses}

The data of the visible platform, escape acquisition, and memory persistence tests were not normally distributed, and therefore they were transformed into $\log 10$ data. The data of the visible platform test and the acquisition phase of spatial memory test were analyzed using two-way repeated measures analysis of variance (ANOVA). The memory persistence tests data were analyzed using two-way ANOVA. The post hoc Holm-Sidak method test was executed wherever appropriate.

The data of the body and hippocampal weights as well as the increase (delta) of body weights of the rats were analyzed using independent t-test. Unpaired t-test was also used to measure the differences between groups in the hippocampal estrogen and ER $\beta$ levels. The Pearson correlation or the Spearman correlation tests were used to assess the correlation between the hippocampal estrogen levels with the spatial memory persistence test data and the hippocampal ER $\beta$ levels.

The statistical analyses were performed using either SPSS (version 19) or Sigmastat (version 3.1) software. All data were presented as the means \pm SEM and the significance levels were set at $\mathrm{p}<0.05$.

\section{Results}

The body and hippocampal weights of rats

Table 1 presents the data on the body and hippocampal weights of all rats. The independent $t$ test revealed no significant difference between the control and exercise group in the body weights before and after exercise, as well as the increase of body weights. There was also no significant difference in the hippocampal weights between the exercise and control groups.

\section{The sensory-motor functions of rats}

Visible platform test. Both exercise and control groups performed equally well on the eight trials of the two consecutive days of the visible platform test (Fig. 1). Two-way ANOVA of the $\log 10$ of escape latencies during the visible platform test did not show any significant main effects of groups and days. However, there was a significant main effect of groups $\mathrm{x}$ days interaction. Post-hoc tests using Holm-Sidak method (complete data not presented for the sake of brevity) showed a significant difference in the escape latency between the exercise and the control groups in trials 3 $(t=1.806 ; p=0.076)$, and $6(t=3.137 ; p=0.003)$ only. Overall, however, there was no significant difference in the sensory-motor functions between both groups of rats.

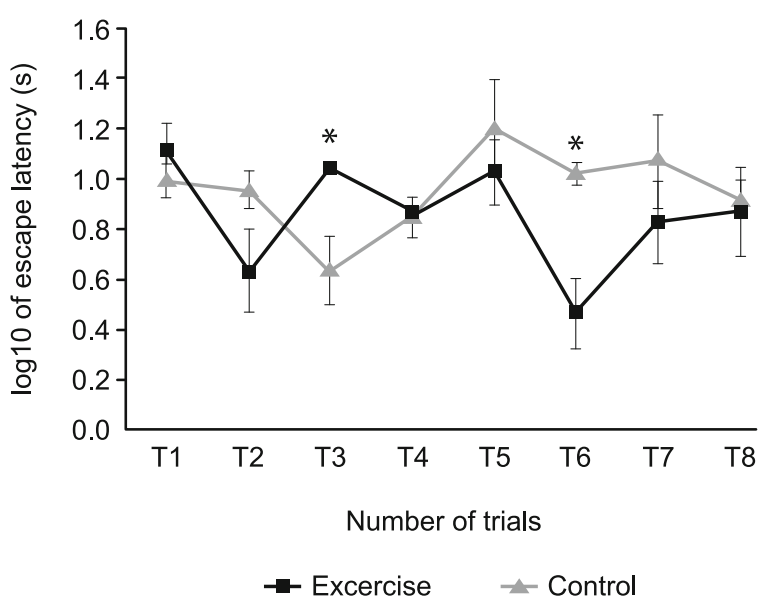

Fig. 1. Mean \pm SEM of the $\log _{10}$ of escape latency (s) of exercise group and control group rats during 2 consecutive sensory-motor test days of the Morris water maze procedure; T, trial. Results of two-way ANOVA. Groups; df $=1,64 ; F=2.632 ; p=0.110$. Days; $d f=1,64 ; F=2.044$; $\mathrm{p}=\mathbf{0 . 0 6 3}$. Groups $x$ day interaction; $\mathrm{df}=2,64 ; \mathrm{F}=\mathbf{2 . 7 7 5} ; \mathrm{p}=\mathbf{0 . 0 1 4}$. ANOVA - analysis of variance; df - degree of freedom; F - F value; p - p value; *, p $<0.05$.

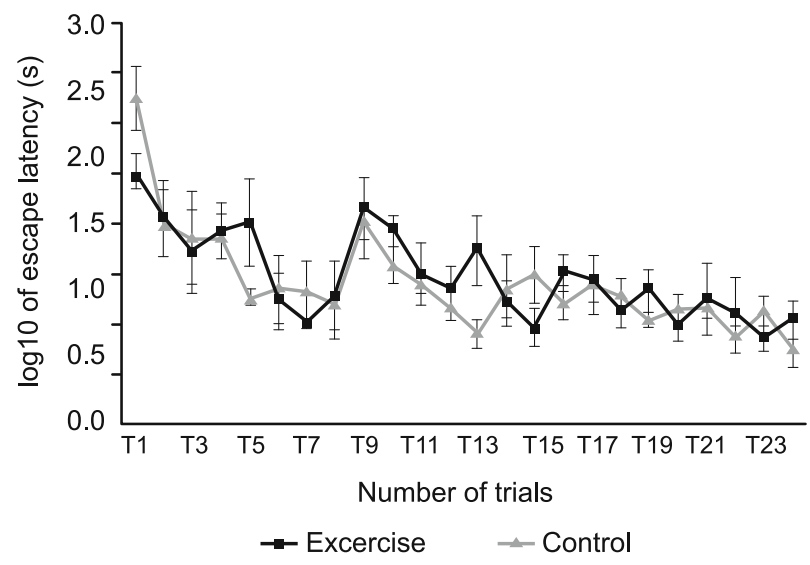

Fig. 2. Mean \pm SEM of the $\log _{10}$ of the escape latency (s) of exercise and control groups of rats during 3 consecutive escape acquisition test days of the Morris water maze procedure; $T$, trial. Results of two-way ANOVA repeated measures. Groups; $d f=1,184 ; \mathrm{F}=0.345 ; \mathrm{p}=0.573$. Day/trial; $d f=23,184 ; F=5.394 ; p=<0.001$. Groups $x$ day/trial interaction; $d f=23,184 ; F=0.763 ; p=0.774$. ANOVA - analysis of variance; df - degree of freedom; $F$ - F value; $p$ - $p$ value.

\section{The effect of exercise on spatial memory}

Escape acquisition test. The $\log 10$ data of escape acquisition tests are shown in Figure 2. The two-way repeated measures ANOVA of these data showed a significant main effect of day/ trial, but not groups nor groups $\mathrm{x}$ day/trial. There was no significant difference in the escape latencies between the exercise and control groups.

Memory persistence test. The memory persistence ability was analyzed from the $\log 10$ transformed data of escape latencies of first trials of day 3 (trial 17), day 10, and day 17 (Fig. 3). Two-way ANOVA of these data showed that there were signifi- 


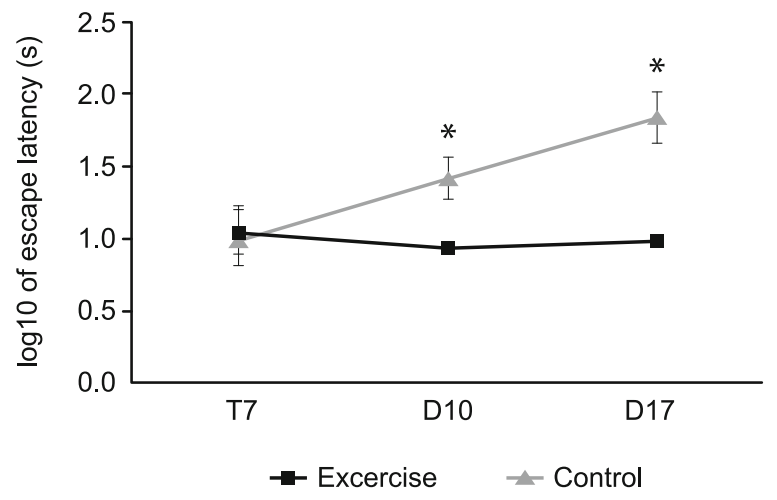

Fig. 3. Mean \pm SEM of the $\log _{10}$ of the escape latency (s) in memory persistence test of the Morris water maze test; T17, the first trial of day 3 Morris water maze test; D10, the trial at day 10; D17, the trial at day 17. Results of two-way ANOVA. Groups; $\mathrm{df}=1,24 ; \mathrm{F}=14.356$; $p<0.001$. Days; $d f=2,24 ; F=3.504 ; p=0.046$. Groups $x$ day interaction; $\mathrm{df}=2,24 ; \mathrm{F}=4.868 ; \mathrm{p}=0.017$. ANOVA - analysis of variance; df - degree of freedom; $F-F$ value; $p$ - $p$ value; *, $p<0.05$.

cant main effects of groups, days, and groups x day interaction. Post-hoc tests using the Holm-Sidak method (complete data not presented) showed that the escape latency of exercise group was significantly shorter than that of the control group in day $10(\mathrm{p}=$ $0.023)$, and in day $17(\mathrm{p}=0.000)$.

The effect of exercise on hippocampal estrogen and ER levels

Figure 4 presents the data of hippocampal estrogen and ER $\beta$ concentration of the exercise and control groups. The mean level of hippocampal estrogen in the exercise group (33.794 \pm 4.760 $\mathrm{pg} / \mathrm{mL} / 100 \mathrm{mg}$ tissue weight) was significantly higher than that of the control group $(20.552 \pm 2.057 \mathrm{pg} / \mathrm{mL} / 100 \mathrm{mg}$ tissue weight $)$ $(p<0.05)$. On the other hand, independent $t$ test of the data of hippocampal ER $\beta$ concentration showed no significant difference between the exercise $(27.8 \pm 1.5 \mathrm{pg} / \mathrm{mL} / 50 \mathrm{mg}$ tissue weight $)$ and control $(19.6 \pm 3.3 \mathrm{pg} / \mathrm{mL} / 50 \mathrm{mg}$ tissue weight) groups.

\section{Correlation}

The Spearman correlation test revealed a significant $(\mathrm{p}<$ $0.05)$ negative correlation $(r=-0.709)$ between the hippocampal estrogen levels and the escape latencies of day 17 in the memory persistence test of both groups. The correlation analyses also exhibited a significant $(\mathrm{p}=0.018)$ negative correlation $(\mathrm{r}=-0.939)$ between the hippocampal estrogen and ER $\beta$ levels in the exercise group. On the other hand, there was no significant correlation ( $p$ $=0.598, \mathrm{r}=0.322)$ between the hippocampal estrogen and ER $\beta$ levels in the control group (38).

\section{Discussion}

The present study found that regular physical exercise might not affect spatial learning of ovariectomized rats as has been indicated in the escape acquisition phase of Morris water maze test. However, it may improve spatial memory retention of these rats.

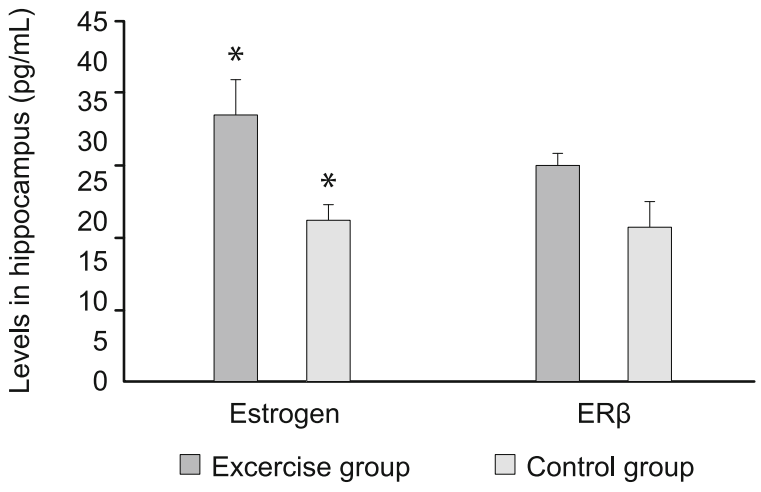

Fig. 4. Mean \pm SEM of the levels of estrogen and ERß in the hippocampus of the exercise and control groups; *, $p<0.05$.

Rats of the exercise group also exhibited significantly higher hippocampal estrogen levels than those of the control group. These estrogen levels inversely correlated to both the escape latencies of day 17 of the memory persistence test and hippocampal ER $\beta$ levels.

The improvement of the spatial memory retention of the ovariectomized rats of the exercise group might have been caused by the increase of the hippocampal estrogen level as was revealed by correlation analyses. Studies have demonstrated that hippocampus is capable of carrying out extra-gonadal steroidogenesis $(29,30)$. This steroid synthesis is thought to be mediated by IL-6 (39), which is produced by contracting muscles during physical exercise (26). IL-6 in circulation is capable of triggering extra-gonadal aromatization by increasing aromatase activity in the adrenal cortex, bone, and adipose tissue (26). IL-6 is also thought to be involved in the regulation of neurosteroid synthesis in brain (39).

Long-term memory formation requires the activation of several kinases (PKC, CaMKII, PKA, and ERK), expression of glutamate receptors (AMPA, NMDA and mGluRs receptors) and synthesis of proteins (adhesion molecules, cytoskeleton proteins, synaptic proteins) $(40,41)$. Ovariectomy leads to a decrease in total protein synthesis in the hippocampus (42), whereas estrogen has the ability to induce second messenger systems, which results in these kinases activation, protein synthesis, gene expression, as well as actin signaling cascades activation (43).

The study by Liu et al. has shown that estrogen increased the number of spines and dendritic branching of rat hippocampal neurons; the expression of synaptic proteins such as synaptophysin and post-synaptic density protein (PSD-95); phosphorylation of CREB, as well as the expression, phosphorylation, and trafficking of subunit GluR1 of AMPA receptors (44). Estrogen also activates metabotropic glutamate receptors, which subsequently modulates second messenger signaling. This brings about the stimulation of specific intracellular mechanisms including the activation of kinases, such as mitogen-activated protein kinase (MAPK) (43). The activation of MAPK pathway causes the phosphorylation of CREB, a transcription factor, which leads to gene transcription of protein synthesis. Synthesized synaptic proteins facilitate morphological 
changes of synaptic structure, which in turn leads to an increase in synaptic function and connectivity (45-47).

The improvement of spatial memory after regular physical exercise may also implicate neurotrophins, such as BDNF and IGF. Previous studies reported that regular physical exercise increased the expression of BDNF and its receptor (TrkB) $(15,17$, 48). BDNF has been known to increase the synaptic signal and response, number of synapses, and axonal branches. It improved overall synaptic function as well as spatial learning and memory retention in a Morris water maze task $(19,49)$. The improvement of spatial memory retention was also associated with the increase of IGF-1 in rats, which performed regular physical exercise (22). There were indications that IGF-1 interacts with BDNF in the regulation of cognitive function in the hippocampus. The addition of IGF-1 per infusion increased the expression of BDNF in hippocampus (50). In addition, neurotrophin expression is modulated by estrogen (51). It is therefore plausible that the effects of physical exercise on spatial learning and memory depend on the interaction between estrogen and neurotrophins, particularly BDNF and IGF-1.

The present study showed that the hippocampal estrogen levels were inversely proportional to the hippocampal ER $\beta$ levels in the exercise group but not in the control group. This is in agreement with the in vitro study, which demonstrated that the addition of estrogen in rat hippocampal tissue culture caused a decrease in the expression of ER $\beta$ (32). Thus, the mechanism by which the increase of estrogen levels suppresses ER $\beta$ expression in the hippocampus is not known. It likely involves inter-dependent regulations between estrogen and IGF-1. In the presence of estrogen, IGF-1 reduces the activity of ER $\alpha$ through PI3K pathway (52). Since ER $\beta$ may act as a target gene of ERs (53), the restriction of $\mathrm{ER} \alpha$ transcriptional activity may bring about a decrease in $\operatorname{ER} \beta$ expression.

In summary, our study found that regular physical exercise might prevent ovariectomy-induced deficit of spatial memory retention ability of Sprague Dawley rats. Physical exercise may exert its beneficial effects on hippocampus via its modulation on the hippocampal estrogen and ER $\beta$ levels. The detailed mechanism of these effects, however, remains unclear at present, and hence necessitates further investigations.

\section{Learning points}

Ovariectomy may lead to hippocampal dysfunctions in both humans and rats

Hippocampal dysfunctions manifest as spatial memory impairment in rats.

A twelve-week regular running exercise may prevent spatial memory deficits by increasing hippocampal estrogen levels.

\section{References}

1. Bjornstrom L, Sjoberg M. Mechanisms of estrogen receptor signaling: convergence of genomic and nongenomic actions on target genes. Mol Endocrinol 2005; 19: 833-842.
2. Stoffel-Wagner B. Neurosteroid metabolism in human brain. Eur J Endocrinol 2001; 145: 669-679.

3. Wise PM, Dubal DB, Wilson ME, Rau SW, Bottner M. Minireview: Neuroprotective effects of estrogen - new insight into mechanism of action. Endocrinology 2001; 142: 969-973.

4. Rocca WA, Bower JH, Maraganore DM et al. Increased risk of cognitive impairment or dementia in women who underwent oophorectomy before menopause. Neurology 2007; 69: 1074-1083.

5. McEwen BS, Alves SE. Estrogen actions in the central nervous system. Endocr Rev 1999; 20: 279-307.

6. Maki PM, Sundermann E. Hormone therapy and cognitive function. Hum Reprod Update 2009; 15: 667-681.

7. Genazzani AR, Bernardi F, Pluchino N et al. Endocrinology of menopausal transition and its brain implications. CNS Spectr 2005; 10: 449-457.

8. Acosta JI, Mayer L, Talboom JS et al. Premarin improves memory, prevents scopolamine-induced amnesia and increases number of basal forebrain choline acetyltransferase positive cells in middle-aged surgically menopausal rats. Horm Behav 2009; 55: 454-464.

9. Ben J, Soares FM, Scherer EB, Cechetti F, Netto CA, Wyse AT. Running exercise effects on spatial and avoidance tasks in ovariectomized rats. Neurobiol Learn Mem 2010; 94: 312-317.

10. Gibbs RB. Long-term treatment with estrogen and progesterone enhances acquisition of a spatial memory task by ovariectomized aged rats. Neurobiol Aging 2000; 21: 107-116.

11. Pan M, Li Z, Yeung V, Xu RJ. Dietary supplementation of soy germ phytoestrogens or estradiol improves spatial memory performance and increases gene expression of BDNF, TrkB receptor and synaptic factors in ovariectomized rats. Nutr Metab (Lond) 2010: 775.

12. Norbury R, Cutter WJ, Compton $\mathbf{J}$ et al. The neuroprotective effects of estrogen on the aging brain. Exp Gerontol 2003; 38: 109-117.

13. McEwen B. Estrogen actions throughout the brain. Recent Prog Horm Res 2002: 357-384.

14. McEwen B, Akama K, Alves S et al. Tracking the estrogen receptor in neurons: implications for estrogen-induced synapse formation. Proc Natl Acad Sci USA 2001; 98: 7093-7100.

15. Franklin TB, Perrot-Sinal TS. Sex and ovarian steroids modulate brain-derived neurotrophic factor (BDNF) protein levels in rat hippocampus under stressful and non-stressful conditions. Psychoneuroendocrinology 2006; 31: 38-48.

16. Rehman HU, Masson EA. Neuroendocrinology of female aging. Gend Med 2005; 2: 41-56.

17. Takeo C, Ikeda K, Horie-Inoue K, Inoue S. Identification of Igf2, Igfbp2 and Enpp2 as estrogen-responsive genes in rat hippocampus. Endocr J 2009; 56: 113-120.

18. Ploughman M, Attwood Z, White N, Dore JJ, Corbett D. Endurance exercise facilitates relearning of forelimb motor skill after focal ischemia. Eur J Neurosci 2007; 25: 3453-3460.

19. Ploughman M. Exercise is brain food: the effects of physical activity on cognitive function. Dev Neurorehabil 2008; 11: 236-240.

20. Pines A, Berry EM. Exercise in the menopause - an update. Climacteric 2007; 10: Suppl 242-246.

21. Erickson KI, Voss MW, Prakash RS et al. Exercise training increases size of hippocampus and improves memory. Proc Natl Acad Sci USA 2011; 108: 3017-3022. 
22. Ding Q, Vaynman S, Akhavan M, Ying Z, Gomez-Pinilla F. Insulinlike growth factor I interfaces with brain-derived neurotrophic factor-mediated synaptic plasticity to modulate aspects of exercise-induced cognitive function. Neuroscience 2006; 140: 823-833.

23. Berchtold NC, Kesslak JP, Pike CJ, Adlard PA, Cotman CW. Estrogen and exercise interact to regulate brain-derived neurotrophic factor mRNA and protein expression in the hippocampus. Eur J Neurosci 2001; 14: 1992-2002.

24. Shimegi S, Yanagita M, Okano H et al. Physical exercise increases bone mineral density in postmenopausal women. Endocr J 1994; 41: 49-56.

25. Hao L, Wang Y, Duan Y, Bu S. Effects of treadmill exercise training on liver fat accumulation and estrogen receptor alpha expression in intact and ovariectomized with or without estogen replacement treatment. Eur J Appl Physiol 2010; 109: 879-886.

26. Simpson E, Rubin G, Clyne $\mathbf{C}$ et al. Local estrogen biosynthesis in males and females. Endocr Relat Cancer 1999; 6: 131-137.

27. Simpson ER, Davis SR. Minireview: aromatase and the regulation of estrogen biosynthesis - some new perspectives. Endocrinology 2001; 142: 4589-4594.

28. Prange-Kiel J, Rune GM. Direct and indirect effects of estrogen on rat hippocampus. Neuroscience 2006; 138: 765-772.

29. Kimoto T, Tsurugizawa T, Ohta Y et al. Cytochrome P450-dependent neurosteroid synthesis in the rat brain hippocampal neurons. International Congress Series 2002; 1233: 127-137.

30. Hojo Y, Murakami, G, Mukay H, Higo S, Hatanaka Y, Ogiue-Ikeda M, Ishii H, Kimoto T, Kawato S. Estrogen synthesis in the brain--role in synaptic plasticity and memory. Mol Cell Endocrinol 2008; 290: 31-43.

31. Rune GM, Wehrenberg U, Prange-Kiel J, Zhou L, Adelmann G, Frotscher M. Estrogen up-regulates estrogen receptor alpha and synaptophysin in slice cultures of rat hippocampus. Neuroscience 2002; 113 : $167-175$.

32. Prange-Kiel J, Wehrenberg U, Jarry H, Rune GM. Para/autocrine regulation of estrogen receptors in hippocampal neuron. Hippocampus 2003; 13: 226-234.

33. Paquette A, Wang D, Gauthier M-S et al. Specific adaptations of estrogen receptor $\mathrm{a}$ and $\mathrm{b}$ transcripts in liver and heart after endurance training in rats. Mol Cell Biochem 2007; 306: 179-187.

34. Wang M, Yu B, Westerlind $K$ et al. Prepubertal physical activity up-regulates estrogen receptor b, BRCA1 and p53 mRNA expression in the rat mammary gland. Breast Cancer Res Treat 2009; 115: 213-220.

35. Morris RGM. Spatial localization does not require the presence of local cues. Learn Motiv 1981; 12: 239-260.

36. Partadiredja G, Bedi KS. Mice undernourished before, but not after, weaning perform better in motor coordination and spatial learning tasks than well-fed controls. Nutr Neurosci 2011; 14: 129-137.

37. Tomlinson D, Wilce P, Bedi KS. Spatial learning ability of rats following differing levels of exposure to alcohol during early postnatal life. Physiol Behav 1998; 63: 205-211.
38. Kaidah S. Persistensi memori spasial dan kadar estrogen jaringan hippocampus tikus Sprague Dawley yang diovariektomi meningkat dengan latihan fisik teratur dan terukur (Indonesian). Yogyakarta; Universitas Gadjah Mada, 2012.

39. Guzmán C, Hernández-Bello R, Morales-Montor J. Regulation of steroidogenesis in reproductive, adrenal and neural tissues by cytokines. Open Neuroendocrinol J 2010; 3: 161-169.

40. Davis S, Laroche S. A molecular biological approach to synaptic plasticity and learning. C R Acad Sci III 1998; 321: 97-107.

41. Dash P, Moore A. Handbook of neurochemistry and molecular neurobiology. 3 ed. New York; Plenum Press, 2007.

42. Hayase K, Tanaka M, Tujioka K, Hirano E, Habuchi O, Yokogoshi H. 17-b-estradiol affects brain protein synthesis rate in ovariectomized female rats. J Nutr 2001; 131: 123-126.

43. Srivastava DP, Waters EM, Mermelstein PG, Kramar EA, Shors TJ, Liu F. Rapid estrogen signaling in the brain: implications for the finetuning of neuronal circuitry. J Neurosci 2011; 31: 16056-16063.

44. Liu F, Day M, Muniz LC et al. Activation of estrogen receptor-beta regulates hippocampal synaptic plasticity and improves memory. Nat Neurosci 2008; 11: 334-343.

45. Minichiello L. TrkB signalling pathways in LTP and learning. Nat Rev Neurosci 2009; 10: 850-860.

46. Grove-Strawser D, Boulware MI, Mermelstein PG. Membrane estrogen receptors activate the metabotropic glutamate receptors mGluR5 and mGluR3 to bidirectionally regulate CREB phosphorylation in female rat striatal neurons. Neuroscience 2010; 170: 1045-1055.

47. Boulware MI, Weick JP, Becklund BR, Kuo SP, Groth RD, Mermelstein PG. Estradiol activates group I and II metabotropic glutamate receptor signaling, leading to opposing influences on cAMP response element-binding protein. J Neurosci 2005; 25: 5066-5078.

48. Schinder AF, Poo M. The neurotrophin hypothesis for synaptic plasticity. Trends Neurosci 2000; 23: 639-645.

49. Mattson MP, Maudsley S, Martin B. BDNF and 5-HT: a dynamic duo in age-related neuronal plasticity and neurodegenerative disorders. Trends Neurosci 2004; 27: 589-594.

50. Carro E, Nunez A, Busiguina S, Torres-Aleman I. Circulating insulin-like growth factor I mediates effects of exercise on the brain. J Neurosci 2000; 20: 2926-2933.

51. Sohrabji F, Lewis DK. Estrogen-BDNF interactions: implications for neurodegenerative diseases. Front Neuroendocrinol 2006; 27: 404-414.

52. Mendez P, Garcia-Segura LM. Phosphatidylinositol 3-kinase and glycogen synthase kinase 3 regulate estrogen receptor-mediated transcription in neuronal cells. Endocrinology 2006; 147: 3027-3039.

53. Wiik A, Hellsten Y, Berthelson P, Lundholm L, Fischer H, Jansson E. Activation of estrogen response elements is mediated both via estrogen and muscle contractions in rat skeletal muscle myotubes. Am J Physiol Cell Physiol 2009; 296: C215-C220. 